\title{
Management of a pilomatrixoma with atypical features
}

\author{
Lauren Christene Strazzulla ${ }^{1}$, Nina Schatz-Siemers ${ }^{2}$, Ioannis Hatzaras*1 \\ ${ }^{1}$ Department of Surgery, New York University School of Medicine, New York, USA \\ ${ }^{2}$ Department of Pathology, New York University School of Medicine, New York, USA
}

Received: March 24, 2016

DOI: $10.5430 /$ crcp.v3n3p28

\author{
Accepted: May 12, 2016 \\ Online Published: June 1, 2016 \\ URL: http://dx.doi.org/10.5430/crcp.v3n3p28
}

\begin{abstract}
In this case we report a 54-year-old man presenting with a large fungating mass that had been identified as a pilomatrixoma on a biopsy from an outside hospital. Based on the atypical clinical and radiographic findings we were concerned that the lesion may have aggressive features and decided to perform a wide local excision with 2 centimeter margins to manage this patient's risk of recurrence. On surgical pathology, the lesion did have characteristics that were concerning for progression to a pilomatrix carcinoma, however, a definitive invasive component was not identified. This case emphasizes the preferred management in pilomatrixoma with atypical features is a wide local excision.
\end{abstract}

Key Words: Pilomatrixoma, Wide local excision, Hair matrix, Malignancy

\section{INTRODUCTION}

Pilomatrixomas are benign cutaneous neoplasms arising from the primitive cells of the hair matrix. These tumors tend to be solitary lesions, that present in the first two decades of life as slow growing, hard, subcutaneous nodules. ${ }^{[1]} \mathrm{Pi}-$ lomatrix carcinoma represents a malignant and extremely rare variant of this tumor that has a greater potential to recur and metastasize. ${ }^{[2]}$ In this case we present a patient with a pilomatrixoma with atypical features concerning for progression to a pilomatrix carcinoma. The tumor was ultimately managed with a wide local excision.

\section{CASE REPORT}

The patient is a 54-year-old man without significant past medical history who initially noticed a "pimple sized" lesion on his upper back several years earlier, which had slowly grown into a large fungating lesion. He then presented to the emergency department complaining of tenderness at the site of the lesion. An MRI with contrast showed a hetero- geneously enhancing, partially solid and partially calcified mass measuring $13.7 \mathrm{~cm} \times 3.3 \mathrm{~cm} \times 10.9 \mathrm{~cm}$ (see Figure 1), without evidence invasion to the surrounding muscle (see Figure 1). In addition, there was infiltrative enhancement of the subcutaneous fat and trapezius muscle deep to the mass, which was thought to be due to adjacent inflammation or tumor spread. There was also asymmetrically increased vascularity in the left paraspinal and intercostal regions. A biopsy performed at an outside hospital was consistent with pilomatrixoma.

A wide local excision with $2 \mathrm{~cm}$ margins was performed given that these clinical and radiographic features were concerning for a locally aggressive tumor. During the operation, the lesion was found to have areas of bleeding, and purulent drainage extending down through the subcutaneous tissues and to the muscle fascia. Given the nature of the drainage and the likely infected wound bed, the decision was made to leave the wound open and proceed with definitive reconstruction at

\footnotetext{
${ }^{*}$ Correspondence: Ioannis Hatzaras, MD, MPH, FACS; Email: Ioannis.Hatzaras@nyumc.org; Address: Division of Surgical Oncology, NYU School of Medicine, 462 First Avenue, NBV 15 N1, NY, 10016, New York, USA. 
a later time. The wound was dressed with Daikin's solution soaked kerlex to prevent infection, and the patient received TID dressing changes for the first 3 days post-operatively. A wound vacuum was then placed and 11 days following the initial procedure the wound was eventually closed using split thickness skin grafts taken from each thigh.

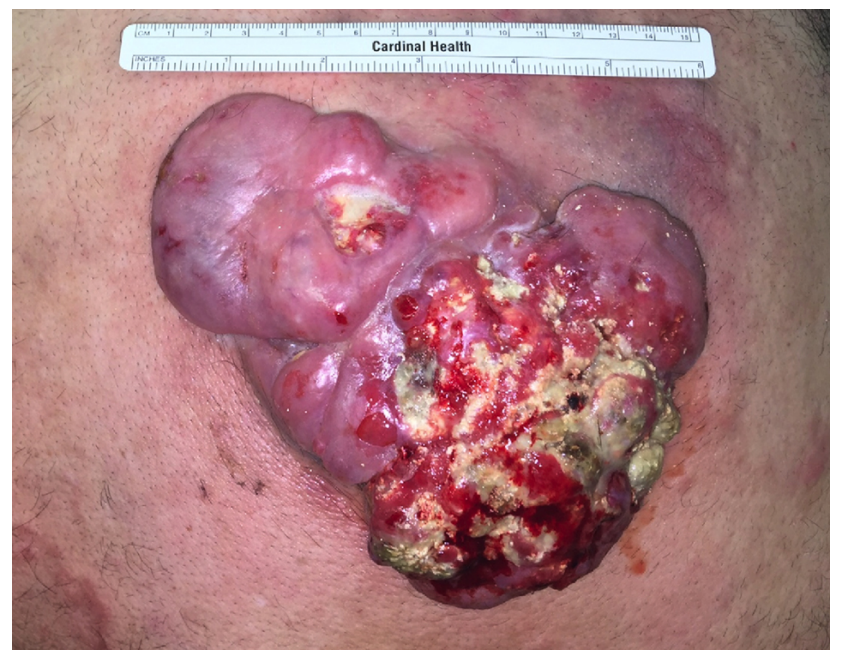

Figure 1. This image shows the $13.7 \mathrm{~cm} \times 3.3 \mathrm{~cm} \times$ $10.9 \mathrm{~cm}$ fungating lesion, which was noted to be draining pus, blood and serous fluid on physical exam

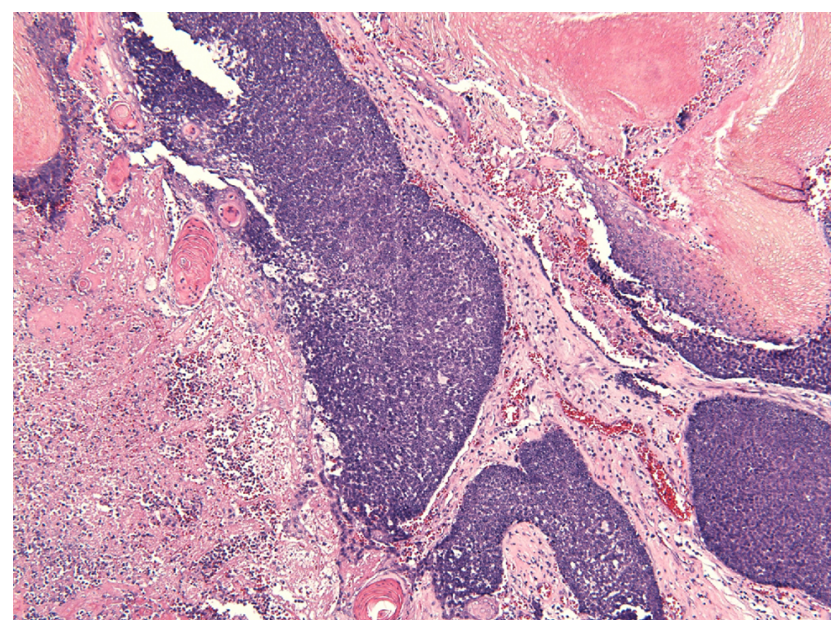

Figure 2. This slide shows infiltrating islands of basal cells with abrupt keratinization and transition to "ghost" cells (anucleate squamous cells) [right] and necrosis [left]. 100× magnification, $\mathrm{H} \& \mathrm{E}$ staining.

\section{Discussion}

The histopathologic features that suggest a pilomatrix carcinoma as opposed to a benign pilomatrixoma include irregular masses of basaloid cells extending throughout the tumor, irregular infiltration of the surrounding tissue, necrosis, and high mitotic count. While benign pilomatrixomas tend to have exuberant keratinization and shadow cell formation occurring in an organized manner toward the center of the tumor, malignant tumors will show less frequent keratinization and haphazard shadow cell formation. Infiltration of the tumor into underlying skeletal muscle and perineural and vascular invasion are also suggestive of malignancy. ${ }^{[2,3]}$

The lesion in this case posed a diagnostic challenge because it had many features that were concerning for malignancy including notably large tumor size with nests of basaloid cells extending throughout the tumor, and extensive necrosis (see Figure 2). There was also irregular infiltration into the surrounding tissue and a high level of mitotic activity, albeit, no evidence of invasion was identified (see Figure 3). Yet at the same time, atypical basal cells were not evident in the lesion nor were histopathologic signs of advanced malignant behavior including vascular and perineural invasion.

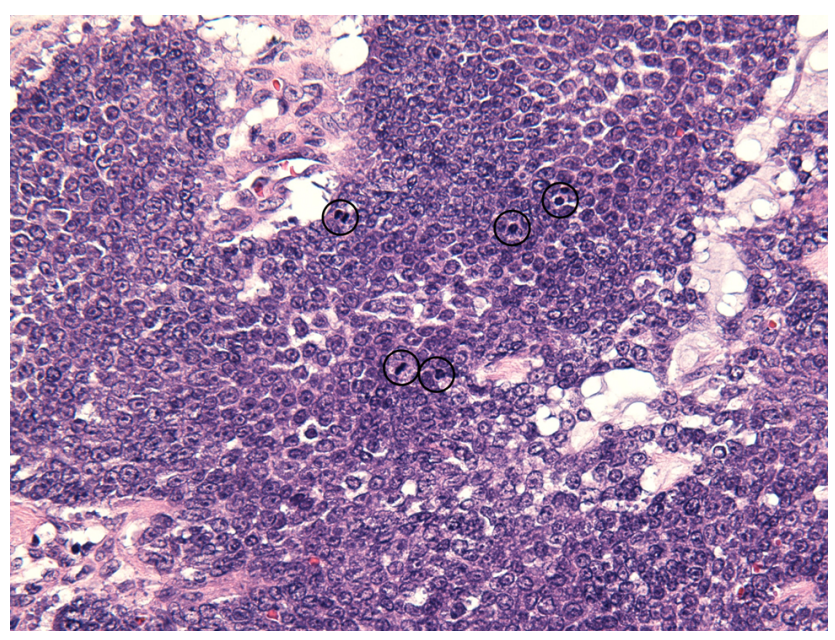

Figure 3. This is a high-power magnification showing basal cells with frequent mitoses (circled). $400 \times$ magnification, H\&E staining.

Overall, pilomatrix carcinoma is a rare lesion, which can be difficult to confidently distinguish from an atypical pilomatrixoma. This case highlights the fact that giant pilomatrixomas with atypical clinical and histologic features may have characteristics associated with malignant pathology. The impact this has on prognosis and the risk of recurrence is not well understood. Given that pilomatrix carcinomas have a greater tendency to recur when managed with simple excision, wide excision is the preferred management for a lesion with atypical characteristics as presented in this case. ${ }^{[4,5]}$

\section{Conflicts of InTERest Disclosure}

The authors declare no conflict of interest. 


\section{REFERENCES}

[1] Forbis R, Helwig E. Pilomatrixoma (calcifying epithelioma). Arch Dermatol. 1961; 83: 606-18. PMid: 13700704. http://dx.doi.o rg/10.1001/archderm.1961.01580100070009

[2] Sau P, Lupton GP, Graham JH. Pilomatrix carcinoma. Cancer. 1993; 71: 2491-8. http://dx.doi.org/10.1002/1097-0142(199304 15) $71: 8<2491::$ AID-CNCR2820710811>3.0.C0;2-I

[3] Steven K, Soyer HP, Hodl S, et al. Morphological stages of Pilomatricoma. Am J Dermatopathol. 1996; 18(4): 333-8. http: //dx.doi.org/10.1097/00000372-199608000-00001
[4] Melancon JM, Tom WL, Lee RA, et al. Management of Pilomatrix Carcinoma: A case report of successful treatment with Mohs Micrographic Surgery and Review of the Literature. Dermatol Surg. 2011; 37: 1798-1805. PMid: 22093235. http://dx.doi.org/10.1111 /j.1524-4725.2011.02170.x

[5] Kaddu S, Soyer HP, Wolf IH, et al. Proliferating pilomatricoma. A histopathologic simulator of matrical carcinoma. J Cutan Pathol. 1997; 24: 228-34. PMid: 9138114. http://dx.doi.org/10.11 11/j.1600-0560.1997.tb01586.x 